\title{
Gestão democrática na escola pública: uma experiência educacional do MST
}

\author{
Neusa Maria Dal Ri \& Candido Giraldez Vieitez \\ Universidade Estadual Paulista, Brasil
}

\begin{abstract}
Resumo
O objetivo deste trabalho é discutir a pedagogia do Movimento dos Trabalhadores Rurais Sem Terra por meio da análise dos principais elementos pedagógicos presentes na Escola Municipal de Ensino Fundamental Construindo o Caminho. A investigação revelou que a Escola sobre a qual o Movimento detém a posse tem funcionamento e organização diversos dos usualmente encontrados nas escolas oficiais, colocando em epígrafe categorias educacionais como a união do ensino com o trabalho e a gestão democrática compartilhada entre alunos, professores, funcionários e comunidade.
\end{abstract}

Palavras-chave

Educação democrática; Autogestão; MST; Trabalho

\section{Introdução}

O objetivo deste artigo é apresentar e discutir um conceito teóricoprático de democratização da escola pública que transcende a categoria formal-oficial de gestão democrática. Para tanto, abordamos a pedagogia do Movimento dos Trabalhadores Rurais Sem Terra (MST), porém mediada pelo exame da experiência desenvolvida na Escola de Ensino Fundamental pública denominada de Construindo o Caminho (ECC).

O movimento pela gestão democrática na escola irrompeu da comunidade escolar no bojo das lutas travadas nos anos 1970 e 1980 contra 
a ditadura e pelo Estado de Direito no Brasil conduzidas, sobretudo, pelas associações de professores, funcionários e estudantes (Prais, 1990; Dal Ri, 1997). Deste modo, tudo indica que o movimento democrático foi uma das forças ativas mais importantes que se encontra presente na raiz dos acontecimentos que levaram à emergência do preceito de gestão democrática na escola no país.

O princípio da gestão democrática na escola pública figurou, de forma genérica, na Constituição promulgada em 1988, que foi o ato legal de maior estatura a sedimentar a flexão histórica realizada com a passagem da ditadura ao regime democrático. Esse preceito foi reafirmado na Lei de Diretrizes e Bases da Educação Nacional (LDB) ${ }^{1}$, n. 9394, sancionada em 1996, na qual estão previstas as participações dos profissionais da educação na elaboração do projeto pedagógico da escola e das comunidades escolar e local em conselhos escolares e equivalentes (art. 14%).

$\mathrm{Na}$ Constituição e na LDB, os legisladores optaram por formulações genéricas propiciando aos estados e municípios certa margem de liberdade para a implantação da gestão democrática. Apesar disso, a literatura vem demonstrando que um modelo básico, com poucas variações e nucleado pelo Conselho de Escola, foi adotado pelos poderes públicos.

A categoria central da gestão democrática oficial é a idéia de participação. Essa participação abre um espaço para a atuação administrativo-pedagógica da comunidade escolar e pais de alunos, contudo, o âmbito da jurisdição sobre o qual essa atividade tem efeito é restrito.

O MST também desenvolve a idéia de gestão democrática, porém com uma perspectiva diferente daquela utilizada pelo Estado. O seu objetivo vai além da participação, uma vez que sinaliza com a idéia de controle da escola pelas forças populares, ou seja, por professores, funcionários, alunos, pais e comunidade local.

Neste artigo, procuramos mostrar que a posse da Escola Construindo o Caminho pelas forças populares é um dos pré-requisitos para o exercício do controle e para a instauração do autogoverno democrático nessa escola. Esta característica tem significativo impacto na prática pedagógica, em particular na que diz respeito àqueles elementos escolares que mais imediatamente atuam sobre a formação da visão de mundo dos educandos. 
A organização da atividade educativa na ECC está baseada nas diretrizes pedagógicas do MST. Essas diretrizes pedagógicas, por sua vez, encontram-se articuladas com certas características sociopolíticas do MST as quais Ihe propiciam uma feição ponto sui generis no conserto dos movimentos e organizações populares.

A concepção de educação do MST comporta vários aspectos teóricos e ideológicos, bem como diversas práticas educacionais (cf. Caldart, 2000). Para os propósitos deste artigo, no entanto, tomaremos apenas os aspectos que consideramos elementares ou básicos, ligados à gestão democrática, e sobre os quais o Movimento vai buscando erigir uma pedagogia.

Nesta reflexão sustentamos que os elementos básicos presentes na concepção educacional da ECC estão em correspondência com a práxis econômica e com a organização política de base do MST e que há, também, influências teóricas educacionais.

Os dados empíricos trabalhados neste texto foram coletados por meio de entrevistas e observações. Foram entrevistados uma das professoras, quatro alunos que no momento do levantamento de dados ocupavam cargos de coordenadores nas instâncias deliberativas da escola, alunos de $3^{\underline{a}}$ e $4^{\underline{a}}$ séries, quatro pais de alunos, três associados e três dirigentes da Cooperativa de Produção Agropecuária União do Oeste (Cooperunião) do Assentamento².

\section{Características da educação do MST}

Nas sociedades de classes, a educação dominante é a educação das classes dominantes, ainda que no capitalismo a ideologia pedagógica oficial apresente-se travestida na forma de conhecimentos, valores e habilidades universais.

O MST é uma organização que diverge da ordem social capitalista e, dessa forma, entende que o ensino oficial não acolhe as necessidades de formação dos seus membros. Nesse sentido, as escolas do MST e aquelas públicas sobre as quais detém a posse são organizadas de forma a atender às suas características e necessidades específicas, dentre as quais se destaca a formação dos militantes e dos profissionais necessários para desenvolver o seu programa econômico nos assentamentos e acampamentos. 
O MST necessita que o militante tenha uma formação política, porém, isso não é suficiente. Além dessa qualidade, o Movimento precisa que o seu membro adquira também capacitação técnica, bem como desenvolva as aptidões para a organização coletiva da vida social, da produção e de outras atividades econômicas.

Esses requisitos derivam de uma característica organizacional insólita do MST no contexto das organizações populares, ou seja, o fato de que três instâncias da realidade social, a política, a econômica e a social, que se encontram normalmente separadas nas práxis de outras organizações, no MST encontram-se organicamente reunidas.

O membro do MST, diversamente do membro de organizações como partidos e sindicatos, encontra-se articulado ao Movimento não apenas por ideologia e funções políticas, mas também pelo fato de estar inserido em alguma das suas estruturas organizacionais de base que são o acampamento e o assentamento.

Além da demanda crucial de organizar a produção, o assentamento coloca outros desafios ao MST. Destacamos dois problemas: a manutenção dos jovens nos assentamentos e a permanência dos assentados no Movimento.

Para os assentados a reforma agrária realizou-se e, aparentemente, eles não teriam mais motivo para dar continuidade à luta. Ao mesmo tempo, os jovens dos assentamentos sentem-se atraídos pela vida urbana, o que coloca em risco a continuidade dos empreendimentos obtidos com tantas dificuldades. Assim, para o MST, trata-se tanto de garantir a exeqüibilidade do assentamento, quanto de manter esses segmentos integrados ao Movimento com os objetivos de avançar na luta pela reforma agrária e continuar desenvolvendo um modo alternativo de produção.

Em suma, o MST é um movimento de luta e ao mesmo tempo o demiurgo de uma economia distinta da economia burguesa dominante. É um sujeito ativo e até altissonante na luta de classes na ordem social brasileira. Mas, a sua luta, diversamente do que ocorre com as demais entidades populares, ocorre também imediatamente no terreno da organização da produção. A reivindicação da reforma agrária, não é apenas a reivindicação de acesso à terra, de distribuição de terra para quem não a tem, mas a exigência do direito de promover in continenti uma reorganização não capitalista das 
relações de produção num segmento da economia agrária (cf. Dal Ri \& Vieitez, 2008).

A opção do MST ao criar escolas próprias e ao tomar posse de escolas públicas reflete as determinantes apontadas anteriormente. Em suas escolas, como, por exemplo, no Instituto de Educação Josué de Castro, localizado na cidade de Veranópolis, o MST mantém cursos como os de Formação de Professores, Técnico em Administração de Cooperativas e de Administração de Assentamentos, Enfermagem-Sáude, entre outros.

Já tivemos a oportunidade, em outros trabalhos (Dal Ri, Vieitez, 2004; Dal Ri, Vieitez, 2008), de demonstrar que esses Cursos expressam a preocupação do Movimento com a educação escolar das crianças nos acampamentos e assentamentos (formação de professores) e revelam a sua disposição em promover formas variadas de cooperação, em especial a criação de cooperativas de trabalho coletivo e de gestão democrática.

Porém, o nosso objeto de estudo aqui, a ECC, é uma escola de ensino fundamental pública e, dessa forma, segue a pauta de uma escola de mesmo nível. No entanto, demonstraremos que também ela está nucleada pela proposta pedagógica do MST.

Em seguida, destacamos as instâncias estratégicas que fazem com que a atividade de educação escolar do MST configure-se como um processo pedagógico próprio, significativamente distinto daquele que é praticado nas escolas oficiais, mesmo em uma escola pública, o que é possível dada a posse da escola pelo Movimento.

\section{A proposta educacional do MST e gestão democrática na escola}

"A pedagogia do MST hoje é mais do que uma proposta. É uma prática viva, em movimento" (MST, 2001b: 19).

A afirmação de que o MST criou uma nova pedagogia pode ser polêmica, porém, ao elaborar e implantar uma nova proposta de educação em suas escolas, o Movimento acabou criando uma nova forma de trabalhar com as matrizes pedagógicas ou com as pedagogias construídas historicamente.

Por pedagogia o MST (1999: 6) entende "o jeito de conduzir a formação de um ser humano". E quando se refere às matrizes pedagógicas, 
- Movimento identifica pedagogia com algumas práticas ou vivências fundamentais para o processo de humanização das pessoas, o que ele também denomina de educação ${ }^{3}$.

\subsection{Princípios filosóficos e pedagógicos do MST}

Para o MST (1999), princípio diz respeito a idéias e formulações que são referências para o seu trabalho em e de educação. Para o Movimento, os princípios são os pontos de partida das ações, porém eles não surgem antes da prática, ao contrário, já são resultados de práticas e de experiências acumuladas em anos de trabalho educacional.

Os princípios filosóficos dizem respeito à visão de mundo, às concepções mais gerais em relação à pessoa humana, à sociedade e à educação.

Os princípios pedagógicos referem-se à forma de fazer e de pensar a educação para a concretização dos princípios filosóficos. Abarcam os elementos que são essenciais e gerais na proposta de educação, em especial aqueles ligados à reflexão metodológica, ou seja, esses princípios referem-se mais à dinâmica do ensino e da aprendizagem.

Dentre os princípios pedagógicos que o MST (1999) enfatiza em sua proposta, interessam-nos aqui particularmente três: a) educação para o trabalho e pelo trabalho; b) gestão democrática; c) auto-organização dos estudantes.

A assertiva da gestão democrática juntamente com a união do ensino e trabalho, torna a organização das escolas do MST bastante diferenciadas e originais, como veremos posteriormente.

As teorias sociológicas e educacionais subjacentes ou explícitas à proposta do MST podem ser verificadas por meio dos autores utilizados e pela prática pedagógica escolar. Dentre esses autores, sobressai a influência dos educadores soviéticos, em especial Pistrak e Makarenko, na organização e funcionamento das escolas. 
2.2. Concepção de gestão escolar: democracia, coletivismo e auto-organização dos alunos

A organização e a gestão da escola são elementos fundamentais de qualquer sistema ou unidade de ensino, pois, dependendo de como elas se processam, a vivência na escola pode ser democrática ou não. Para vivenciar a democracia, o MST propõe para as suas escolas a gestão democrática, a auto-organização dos alunos e o coletivismo.

Para o Movimento a gestão democrática compreende dois pontos fundamentais: a direção coletiva dos processos pedagógicos; e a participação dos envolvidos no processo de gestão escolar.

A direção coletiva de cada processo pedagógico implica a participação efetiva da comunidade na gestão da escola, bem como a relação desta com o conjunto de escolas ligadas ao Movimento e sua subordinação crítica e ativa aos seus princípios (MST, 1996). Segundo o MST (1999: 9), a direção coletiva é uma forma de garantir a participação de todas as pessoas na tomada de decisões, de dividirem-se as tarefas e as funções de acordo com as qualidades e as aptidões pessoais e, também, de superação do paternalismo e do presidencialismo.

O Movimento (1999) entende por auto-organização o direito dos educandos a se organizarem em coletivos, com tempo e espaço próprios, para analisar e discutir as suas questões, elaborar propostas e tomar decisões com o objetivo de participarem como sujeitos da gestão democrática do processo educativo e da escola.

A expressão auto-organização dos estudantes é tomada de Pistrak (2002) pelo MST para especificar o processo de criação do coletivo de alunos das suas escolas.

De acordo com Pistrak (2002), a aptidão para o trabalho coletivo é adquirida na prática, realizando-se o trabalho coletivo. A aptidão para analisar cada problema novo como organizador pressupõe hábitos de organização adquiridos durante o desempenho de diversas funções exercidas pela criança no contexto de diferentes organismos. Essa aptidão será desenvolvida na medida em que as crianças gozem de liberdade e de iniciativa para decidirem sobre as questões relativas à sua organização. 
Nas argumentações de Pistrak (2002), duas visões sobressaem. A primeira refere-se ao seu conceito de aptidão. Ao entender o indivíduo em relação com a sociedade e no coletivo, Pistrak rompe com a visão individualista burguesa de aptidão, ou com aquilo que Bowles e Gintis (1976) denominaram de dom.

A segunda diz respeito à visão que o autor tem de criança. Para ele, a criança não é um ser que deve ser preparado para ser membro da sociedade. Ao contrário, as crianças já são membros da sociedade, têm seus problemas, interesses, objetivos, ideais e já estão ligadas à vida dos adultos e da sociedade. Dessa forma, a auto-organização deve ser para elas um trabalho sério e de responsabilidade. A forma da auto-organização das crianças proposta por Pistrak (2002: 176) é a do coletivo infantil.

Além da idéia de auto-organização dos alunos, Pistrak foi um dos formuladores da escola do trabalho que permeou a formação politécnica na URSS nos anos iniciais da Revolução de 1917. Pistrak era defensor incondicional da ligação entre o ensino e o trabalho produtivo.

Makarenko é outro autor com influência na proposta educacional do MST. Ao lado da educação dos sentimentos e do trabalho, o coletivo é o outro grande motivo da pedagogia de Makarenko (2002a, 2002b).

Makarenko estava convencido de que o ideal de criança abstrata, advinda das teorias e visões da filosofia especulativa e do dogmatismo religioso, não existia. A partir das suas experiências na Colônia Gorki, amadureceu as suas hipóteses sobre a pedagogia como ciência da educação e defendeu a autonomia da pedagogia, marcando o campo educacional como objeto diferenciado dos demais campos científicos.

Para Makarenko a solução do problema pedagógico estaria na constituição de um novo objeto da pedagogia, não mais a criança e sim a coletividade. Porém, a coletividade não poderia ser tomada como uma abstração, mas sim como um novo organismo social, criado pela experiência revolucionária, tal como os sovietes.

Partindo dos conceitos fundamentais do materialismo histórico de Marx e, principalmente, das contribuições da análise sociológica de Lenin, Makarenko construiu um projeto educacional no qual as diferentes personalidades das crianças pudessem ser trabalhadas no sentido da 
construção de uma nova sociedade. Desse modo, a proposta de Makarenko é organizada tendo por base os princípios da instrução geral, do trabalho produtivo e a "[...] constituição dialética da coletividade em seus diferentes aspectos [...]. Aos professores caberia a tarefa principal de instruir, de educar e ser educado, junto aos alunos, na vida coletiva autogestionária" (Luedemann, 2002: 19).

Dentre os elementos fundamentais do projeto de Makarenko destacase a autogestão, considerada como o principal processo educacional e como uma verdadeira educadora do coletivo.

De acordo com Makarenko (2002a: 292-298), o órgão fundamental da autogestão é a assembléia geral dos educandos. A assembléia deve ser aberta, isto é, nela todos os membros da coletividade têm o direito de estar presente e de manifestar-se. A presidência da assembléia deve ser eleita e, na medida do possível, todos os membros, por turno, devem assumir essa função. Essa medida é benéfica para incutir nos educandos determinados hábitos sociais e os atrair para uma vida social ativa.

Makarenko relata com entusiasmo os resultados obtidos na Comuna, outra escola dirigida por ele e que era administrada com o processo de autogestão, inclusive a financeira:

Vocês são capazes de imaginar uma coletividade infantil com autogestão financeira? Isto é uma circunstância muito importante: a comuna cobria não só as despesas orgânicas, os salários dos professores, a manutenção dos gabinetes etc., mas também todas as despesas relacionadas com a manutenção das crianças. Além disso, dava ao Estado um lucro líquido de vários milhões de rublos. Isto é uma grande sorte, porque a autogestão financeira é um pedagogo formidável (2002b: 373-4).

Além dos aspectos apontados, Makarenko também afirmava a necessidade de uma disciplina rígida e de uma autoridade conquistada no coletivo e politicamente engajada.

\section{Escola pública de ensino fundamental Construindo o Caminho}

No dia 24 de junho, de 1988, no município de Dionísio Cerqueira, em Santa Catarina, Brasil, dois grupos de famílias, um deles organizado pelo MST, foram assentados em área desapropriada pelo Estado. 
Em 1990, foi fundada a Cooperunião integrada pelo grupo organizado pelo MST. Em 1995, depois de várias reuniões e cursos de formação freqüentados pelas famílias, houve um processo de unificação do trabalho e dos bens. Com a unificação dos grupos, todos os integrantes do assentamento passaram a ser membros da Cooperunião, o que permitiu expandir a produção agropecuária, melhorar os investimentos em maquinário e organizar o trabalho de forma coletiva. Com o passar dos anos, a Cooperunião transformou-se em um exemplo positivo de organização de cooperativa agrária no Brasil e de movimentação econômica para o município e região.

Em 1989, as crianças do assentamento estavam sem escola. Os pais desejavam uma escola no próprio assentamento, porém, sentiram a necessidade de criar uma escola que não apenas ensinasse a ler e a escrever, mas, também, incentivasse e fortalecesse os princípios e valores assumidos pelo Movimento, tais como o trabalho, a participação e a luta (MST, 2001). A partir disso, a comunidade de assentados, com assessoria do Setor de Educação do MST, passou a discutir uma proposta pedagógica para a escola.

Em 1990, a escola foi formalizada atendendo alunos de $1^{\underline{a}}$ a $4^{\underline{a}}$ séries. Houve um embate de anos entre a comunidade assentada e o poder Municipal para implantar e manter a proposta educacional que hoje orienta a ECC (MST, 2001: 14).

A escola trabalha com a metodologia dos temas geradores. Como 0 trabalho com os temas geradores exigia a participação ativa dos educandos e, também, para que eles se sentissem parte integrante do processo de sua aprendizagem, a Comissão de Educação do Assentamento decidiu organizálos em uma cooperativa. A organização das crianças em cooperativa teve como objetivo fazer com que elas, desde cedo, vivessem experiências de organização coletiva de trabalho. Dessa forma, foi criada a Cooperativa Construindo o Caminho que integra os alunos da ECC.

Para regulamentar a cooperativa-escola elaborou-se o Regimento Interno da Educação, o qual foi discutido e aprovado pelos educandos, pela Comissão de Educação do Assentamento e pela comunidade assentada. A escola funciona com duas classes, uma de alunos das $1^{\underline{a}}$ e $2^{\underline{a}}$ séries e outra das $3^{\underline{a}}$ e $4^{\underline{a}}$ séries, e duas educadoras responsáveis por elas. Além das 
professoras, a escola tem uma auxiliar de serviços gerais, todas contratadas pela Prefeitura.

\section{Estrutura, organização e processos escolares}

Neste item, evidenciamos um dos princípios norteadores da organização escolar do MST que é o estabelecimento do vínculo entre o ensino e o mundo do trabalho. Assinalamos, também, o diferencial na pedagogia do Movimento em relação à organização e funcionamento da escola.

\subsection{A escola do trabalho e o trabalho na escola}

A concepção de ensino vinculado ao trabalho não é uma novidade e, tampouco, um método defendido apenas pelos críticos da educação capitalista. No âmbito do pensamento burguês, propôs-se e implantaram-se, em vários momentos da história, escolas ligadas ao trabalho. Entretanto, as idéias principais que sempre estiveram alicerçando essas propostas foram, basicamente, as de que o aluno aprende melhor por meio do trabalho, tornase mais disciplinado e aprende a valorizar o trabalho. Dessa forma, o que une essas idéias é o fato de o trabalho ser considerado de uma forma abstrata, como uma disciplina escolar, portanto, isolada e separada do ato real de produção. Acrescentemos que, nessas condições, o aluno situa-se na categoria de estudante 4 . Ele não mantém nenhum vínculo orgânico com o local de seu aprendizado. Terminado o seu curso ou estágio, o formado deverá integrar o mercado de trabalho.

Pistrak (2002) colocou-se como crítico das abordagens sobre escola e trabalho que havia até então em sua época e elaborou uma proposta de vínculo entre a educação e o trabalho real na produção.

A importância de Pistrak está no fato de que, ao que tudo indica, foi a esse autor principalmente que o MST recorreu, enquanto uma das principais influências teóricas, para pensar um dos princípios da sua pedagogia, "a educação para o trabalho e pelo trabalho" (MST, 1996: 15).

A ligação entre ensino e trabalho produtivo nas escolas do Movimento ocorre da seguinte forma. 
Nos cursos desenvolvidos nas escolas do MST aplica-se a denominada pedagogia da alternância, ou seja, os cursos são organizados em etapas, cada uma delas constituídas por dois tempos: tempo escola e tempo comunidade. O tempo escola é o tempo no qual os alunos desenvolvem um conjunto de atividades do curso e a participação na gestão da escola. O tempo comunidade é o tempo no qual os alunos retornam aos acampamentos ou assentamentos realizando trabalhos produtivos vinculados ao curso ou delegados pelas instâncias do MST.

Os estudantes trabalham também durante o tempo escola no qual ficam na instituição. Eles atuam em três setores básicos: a) na manutenção e conservação da escola; b) nas unidades de produção; c) na gestão coletiva da escola.

Um dos trabalhos mais importantes que os alunos realizam é a gestão da escola, a qual é compartilhada com professores e funcionários. Convém ressaltar que o trabalho realizado nas escolas pelos alunos não é uma simulação laboratorial, mas trabalho real que de algum modo se articula com a economia ${ }^{5}$. Entretanto, o seu significado é ao mesmo tempo educativo, cumprindo, assim, uma das premissas da abordagem pedagógica do MST que é a de ligar organicamente o ensino e o trabalho.

A proposta do MST para as escolas de educação fundamental também preconiza o vínculo entre o ensino e o trabalho produtivo.

Nem sempre as Unidades de Produção precisam ser da escola, mas é bom que estejam vinculadas a ela e integradas ao seu processo educativo. [...]. As Unidades precisam ser trabalhadas como espaços educativos, onde os educandos possam aprender para além dos modos de produzir que já conhecem. [...] As Unidades de Produção podem ser implementadas na escola ou podem ser implementadas pelo assentamento e colocada sob responsabilidade e os cuidados da escola, ou ainda implantadas por uma cooperativa ou associação e aberta à participação dos educandos (MST, 1999: 34-5).

A concepção de vínculo entre ensino e trabalho permeia toda a organização da ECC e o curso está dividido em tempo estudo e tempo trabalho. Essa concepção fica evidente, também, no discurso das crianças entrevistadas.

"Eu gosto da escola. Aprendemos a trabalhar e estudar"6.

"Nos temas geradores, a gente fica quase um ano trabalhando a 
mesma coisa. No tema embelezamento ficamos quase um ano trabalhando, plantando mudinhas, embelezando o assentamento"7.

De acordo com uma das professoras da ECC, as crianças "produzem com o trabalho. E usufruem desse trabalho de algum modo. Por exemplo, as flores. É um trabalho muito real porque tem resultados" (Professora A).

As crianças trabalham na cooperativa que funciona junto à escola, realizam trabalhos domésticos para as suas famílias e, eventualmente, realizam algumas tarefas para a Cooperunião.

As crianças do meio rural geralmente auxiliam as famílias realizando trabalhos domésticos e trabalhos no campo quando se trata de pequena propriedade rural. Essa é uma tradição do campo que se mantém no Assentamento, provavelmente propiciada pelas condições existentes, mas que não tem ligação com a tese da união do ensino e trabalho.

$\mathrm{Na}$ cooperativa dos educandos, as crianças trabalham de fato. Entretanto, essa cooperativa caracteriza-se mais como uma organização para fins pedagógicos do que econômicos. A maior parte da produção e serviços realizada é de valores de uso, embora a cooperativa estabeleça algumas relações mercantis e gere uma pequena renda também, como, por exemplo, por meio da venda de mudas de plantas e flores.

A Cooperativa Construindo o Caminho é constituída por quatro equipes de trabalho que são: serviços gerais; subsistência; limpeza; pedagógica e comunicação. Ao serem indagadas para que serve a cooperativa, as crianças responderam:

"Para ajudar a escola a trabalhar, a plantar, que nem as alfaces, as mudinhas, catar lixo, adubo para colocar no minhocário"8.

"Serve pra ajudar nos serviços, nos trabalhos. É melhor trabalhar em cooperativa, fica melhor. Fica mais bem feito fazendo junto" (Aluna B).

"Serve para ajudar a ler, a escrever e a trabalhar" (Aluno A).

"Se ajudamos. Quando tem algum trabalho a gente se ajuda. Quando alguém não sabe um serviço, vamos lá e ajudamos" 9 .

A avaliação que os pais fazem desse tipo de orientação da escola é também bastante positiva. 
Elas têm o trabalhinho delas lá. Acho que é bom sim, porque ela vai pegando amor no trabalho. Se ela fica só estudando e brincando, chega a época dela trabalhar, e ela não tem amor no trabalho. Assim, vão adquirindo experiência, vão saber se coordenar. Eles aprendem muita coisa. Eles têm as comissões deles. [...] Ensina a criança a se determinar nas coisas (Pai A).

A mãe de um aluno acrescenta que:

O trabalho eles fazem em equipes. Eles fazem na prática também, tem a horta, o viveiro que produzem e distribuem. Eles negociam com a cooperativa [Cooperunião]. Eles fazem a comissão para vender os produtos em troca de carne, alimentação. A gente tem dificuldade, porque foi educado de uma forma. A educação deles é diferente. Eles fazem direitinho. A nossa criançada aqui tem facilidade, tem facilidade de se apresentar, conversar. Tem muita facilidade. Eles negociam direitinho. Eles têm também as tarefas, os coordenadores (Mãe B).

Nas entrevistas que realizamos com as crianças, pudemos perceber o que os pais ressaltaram em suas falas. As crianças demonstraram uma grande facilidade para conversar, posicionar-se sobre a escola e explicar 0 funcionamento da sua cooperativa e, além disso, elas demonstraram, também, que têm conhecimento de praticamente tudo o que ocorre no Assentamento e na Cooperunião.

\subsection{Conteúdos curriculares}

O currículo básico da ECC segue os referenciais da legislação. Nesse âmbito o que distingue os cursos do MST dos oficiais é, sobretudo, a ideologia ou a concepção de mundo veiculada.

A ideologia disseminada na escola oficial procura ocultar a realidade difundindo a visão de que na sociedade, embora exista estratificação social, não existem classes antagônicas. Essa visão de mundo apresenta a sociedade como se essa fosse unívoca.

Contrapondo-se a essa visão, o MST trabalha com a idéia seminal de que o capitalismo é uma sociedade de classes antagônicas, na qual prevalece a dominação e a exploração da burguesia sobre as classes trabalhadoras e que os Sem Terra, como parte da classe trabalhadora, devem lutar pela sua emancipação.

Essa concepção de mundo, no âmbito dos conteúdos curriculares das escolas do MST, manifesta-se, principalmente, por meio de quatro 
mediadores pedagógicos que são: as disciplinas de humanidades, principalmente a de História; a articulação entre os conteúdos disciplinares e a realidade dos acampamentos e assentamentos; a impostação pedagógica geral dos professores e a capacitação visando à organização popular.

Quanto aos conteúdos de História há duas características a ressaltar. A primeira refere-se ao espaço que é reservado ao estudo da história do próprio Movimento. Embora a apropriação da história do Movimento não ocorra apenas por meio dessa disciplina ${ }^{10}$, ela contribui significativamente para a reprodução da identidade dos Sem Terra. A segunda característica é a transmissão para os alunos de interpretações analíticas que não apenas evidenciam o papel histórico das classes subalternas, como também apresentam de forma positiva os seus valores e feitos, os quais aparecem contrapostos aos das classes dominantes. A história trabalhada não se apresenta simplesmente como o passado do Movimento ou da civilização, mas como um passado que se articula com o presente, particularmente com a realidade desse segmento social.

Essa questão é vista da seguinte forma pela professora da ECC,

Temos um calendário histórico do movimento dos Sem Terra que traz as lutas. Não fazemos feriados nas festas nacionais. A escola só pára quando a Cooperativa pára. As datas significativas para nós: 8 de outubro, dia de Che Guevara. [...]. Trabalhamos a história das crianças e dos pais. [Isso] já é o Movimento. E sem o Movimento dos Sem Terra não teríamos essa escola, essa educação. [...]. O Movimento tem essa preocupação. Em resgatar a história não só do Movimento, mas do país em si.

Diferentemente da escola oficial, que ministra conteúdos gerais, com escassa referência a realidades sociais específicas, e cujos problemas apresentados e resolvidos são fictícios ou simplesmente heurísticos, como apontam Baudelot e Establet (1976), o ensino na escola considerada busca constantemente estabelecer vínculos relacionais com a realidade do Movimento, assentamentos e acampamentos.

Esse ensino que contempla a realidade social da qual emergem os educandos, decorre das características do MST, bem como das influências teóricas presentes em sua pedagogia. Uma das formas de ligação entre o ensino e a realidade social é propiciada pela pedagogia da alternância, sobretudo quando os alunos retornam às comunidades de origem ou outra, desenvolvendo atividades produtivas nas cooperativas e assentamentos que visam colocar em prática os conhecimentos adquiridos no tempo escola. 
No caso da ECC, essa ligação entre o ensino e a realidade social encontra-se contemplada, pelo menos em parte, com a aplicação de métodos inspirados nas propostas de Pistrak (2002) e, sobretudo, Freire (1971, 1980) que, respectivamente, propõem o trabalho com os complexos e com as palavras geradoras. Por outro lado, há a preocupação das professoras e dos pais em utilizar os acontecimentos da vida cotidiana no assentamento, na qual - Movimento tem presença marcante, como materiais para a elaboração de atividades pedagógicas.

Quando você deixa o livro didático tem que se apegar a uma outra coisa. Trabalhar com os temas geradores. O que você fala na sala de aula tenta fazer na prática. Tem conteúdos que não dá para articular com os temas geradores. Mas a gente não coloca só o que lê nos livros. [...]. A maior parte dos conteúdos são trabalhados. A parte ecológica. Foi um dos nossos temas geradores. $O$ reflorestamento, que a criança tenha amor à terra. Os de fora achavam que o assentamento era um lugar feio, bagunçado. Uma das formas de mostrar que não é isso é fazer ações que vêm ao encontro da ecologia, do ambiente. Limpar, embelezar, preservar. [...].O que a [criança] aprende na escola contribui para resolver o problema da casa. Quando adulta venha a contribuir para resolver os problemas da comunidade. Formamos também pessoas para o Movimento. Trabalhamos muito a idéia de pertencer ao Movimento, não só à Cooperativa (Professora A).

A impostação pedagógica dos professores está relacionada com a constituição do quadro docente. Na ECC, por se tratar de escola pública, os professores são contratados pela Prefeitura cujos critérios de alocação são diferentes daqueles que o MST utiliza em suas escolas. Entretanto, mediante um processo que envolveu, ao mesmo tempo, conflitos e negociações com as autoridades educacionais municipais, a Cooperunião conseguiu determinar o perfil das professoras. $O$ fato dos professores terem afinidade com o MST garante uma postura ideológica e política mesmo quando os assuntos tratados nas várias disciplinas nada têm a ver com ideologia ou política, ou seja, os professores acabam por transmitir aos seus alunos valores e idéias favoráveis ao Movimento.

Entretanto, observamos que o controle sobre as escolas, necessário para a implantação da pedagogia preconizada pelo Movimento, é bastante problemático mesmo quando as escolas estão localizadas em seus assentamentos. Primeiro, porque a alocação dos professores nas escolas é da alçada do Estado ou das Prefeituras e não do MST. Uma outra razão é que no interior do próprio Movimento nem sempre se observa a disposição 
necessária para a implantação da proposta, tanto por parte dos profissionais quanto das comunidades. Portanto, embora a pedagogia em questão seja uma proposição programática do Movimento e este se empenhe em implementá-la, o processo é complexo e dificultoso.

\subsection{O cerne das relações pedagógicas: o poder na escola}

A organização da escola não costuma ser apresentada como um fator pedagógico importante. Os atores escolares normalmente vivenciam essa organização, sem maiores reflexões ou preocupações, considerando-a um meio para a realização dos objetivos pedagógicos propostos. No entanto, a organização da escola é um importante elemento pedagógico, é um currículo que, por não fazer parte dos conteúdos programáticos explicitados, encontrase oculto.

A ação desse currículo oculto incide sobre a formação dos educandos de diversos modos. Entretanto, o ensinamento mais importante é o que decorre das relações pedagógicas como réplicas, ainda que em clave escolar, das relações sociais dominantes. Desse ponto de vista, a escola transmite aos alunos por meio da vivência das relações escolares, a percepção e a visão de que as relações burocráticas são as relações naturais e eternas da sociedade. Em uma palavra, uma das lições ministrada na escola consiste na visão de que a burocracia é a forma mais racional de organização social, além de ser a única forma eficiente de organização do trabalho.

A ECC tem na organização escolar uma das principais dimensões que a diferencia da escola oficial.

Como indicado em item anterior, os alunos da ECC dividem-se em quatro equipes de trabalho. As crianças escolhem qual a equipe que querem integrar. As equipes elegem um coordenador, um vice-coordenador e um secretário. Os coordenadores das equipes formam o Conselho Deliberativo. Após as escolhas, os coordenadores e os vice-coordenadores reúnem-se para eleger o coordenador geral e o vice-coordenador geral. Acima do Conselho Deliberativo está a assembléia geral da escola da qual participam todos os educandos e as professoras e que se realiza todas as sextas-feiras.

O Conselho elabora a pauta de discussão que é levada para a reunião das equipes e que, posteriormente, é levada à assembléia. 
A cooperativa formada pelas crianças funciona com autonomia, tem normas e divisão de tarefas. As crianças têm direitos e deveres e há previsão de punições para aquelas que não cumprem as suas tarefas ou deveres. $O$ coordenador de equipe ou o coordenador geral pode ser destituído pela equipe ou pela assembléia caso não corresponda às suas atribuições. Há outras punições para aqueles que não cumprem as tarefas. As punições podem ser produtivas ou de conteúdo (MST, 2001, p. 48), tais como, plantar um pé de fruta ou flor e cuidar dele, fazer um cartaz explicando a tarefa não realizada, elaborar um texto ou síntese, fazer uma dramatização, entre outras.

Nós discutimos as tarefas e decidimos. Quem decide as tarefas não é a professora. São as equipes que decidem. Isso é feito nas reuniões de avaliação. É feito pelas equipes reunidas na avaliação. Aí a assembléia decide. Os secretários vão lá na frente, lêem a pauta, apresentam sugestões e decidem. Se uma equipe levantar que vai ganhar tarefa [no caso de punição] terá que fazer. Depende da pessoa. Tem pessoas que ganham bastante [punição], porque elas brigam e não fazem as tarefas. Ele dá soco, coice nas crianças pequenas, e aí a gente reúne tudo numa tarefa só, mas a tarefa é mais difícil. Se o coordenador não fizer as tarefas ele pode perder o cargo. [...] É ruim perder o cargo ${ }^{11}$.

Em resposta à pergunta: quem manda na escola, os alunos disseram:

"Todos mandam na escola. Nós, as professoras, a merendeira, a comissão de educação" (Aluna C):

Todas as crianças mandam na escola porque todas estão lá, menos os pais. Os pais mandam também, porque eles ajudaram a construir a escola e eles têm uma parte da escola. A escola é nossa e deles. Se não fossem eles conquistarem a escola, não teria. Às vezes a Comissão [Comissão de Educação] fala na assembléia da cooperativa (Aluna B).

A Comissão de Educação do Assentamento é composta por seis pessoas e pelas duas educadoras. Um dos membros é eleito coordenador e faz parte, também, do Conselho Social e Político da Cooperunião. A Comissão reúne-se a cada quinze dias e está atenta a questões que se referem desde a administração do prédio escolar até aos conteúdos pedagógicos, avaliações e planejamento anual das atividades.

Enquanto uma das manifestações da gestão democrática e da promoção entre o ensino e o trabalho, as crianças, a partir dos setes anos, participam da assembléia geral da Cooperunião. Elas têm direito à palavra e, ainda, podem votar em alguns itens de pauta, embora de acordo com o Estatuto o direito ao voto seja apenas dos sócios. 
A Construindo o Caminho organiza-se na forma de uma cooperativa de trabalho. Porém, nem todos os temas são colocados à discussão e decisão das crianças, como, por exemplo, a utilização dos recursos repassados à escola pela Secretaria de Educação Municipal, em torno de 500,00 reais mensais, ou a elaboração integral do planejamento pedagógico.

Desse ponto de vista, estamos de acordo com as afirmações de Pistrak e Makarenko que advogam a participação plena das crianças em todos os temas que dizem respeito à escola. Não conhecemos as razões dessa limitação à participação das crianças nesses tópicos. Porém, é necessário levar em conta que essa experiência encontra-se, ainda, em um processo de busca de soluções e, dessa forma, as implicações pedagógicas não podem ser deduzidas a priori. De nossa parte, entendemos que não haveria danos, mas sim vantagens, se às crianças fossem atribuídas uma maior responsabilidade e amplitude na participação, embora pesquisadores que estudaram com empatia a educação do MST, como Bezerra (1999), acreditem que a responsabilidade hoje atribuída às crianças no âmbito educacional do Movimento já é excessiva.

Poderíamos supor que em um ambiente democraticamente regulado, como 0 das escolas, as relações pedagógicas seriam caracterizadas pela ausência de friç̧ões. Ao contrário, a atmosfera democrática parece propiciar uma situação na qual os conflitos latentes, que permanecem reprimidos por longo tempo em um ambiente autoritário, manifestam-se prontamente.

Nas escolas do MST, além do ambiente democrático, há uma orientação pedagógica que estimula a apresentação dos problemas e das tensões para que estes possam ser trabalhados nos diversos coletivos pedagógicos. Dessa forma, o ambiente escolar, em especial o das escolas de ensino médio e superior, apresentam um volume significativo de conflitos.

Podemos tomar como um evento simbólico, representativo dessa atmosfera na qual se estimula a reflexão e ação dos educandos, o seguinte episódio ocorrido na ECC.

Uma das atividades da cooperativa dos alunos é o cultivo de mudas de plantas para uso próprio e comercialização. Cerca de um ano antes de nossa entrevista, a cooperativa Construindo o Caminho negociou com a Cooperunião a aquisição de certa quantidade de mudas. As crianças 
plantaram e cuidaram das mudas. Chegado o momento adequado à venda, as crianças da ECC dirigiram-se à Cooperunião para consumar a transação. As crianças foram atendidas no escritório da Cooperunião, onde Ihes foi transmitido que a cooperativa não tinha mais interesse na compra das mudas $^{12}$. Dias depois, os alunos, que estavam muito bravos, convocaram uma assembléia geral na qual se discutiu o problema e deliberou-se pela reivindicação do cumprimento do acordo de compra e venda. Para pressionar a Cooperunião, os alunos decidiram realizar, naquele mesmo dia, uma passeata até o seu escritório que não fica muito distante da ECC. Quando as crianças estavam preparando os cartazes, faixas e bandeiras do MST para portarem na passeata, foram surpreendidas pelas professoras da escola. Levando em conta que a Cooperunião estava naquele momento recebendo a visita de uma delegação estrangeira, as professoras tentaram demover as crianças do seu intento, pedindo-Ihes que adiassem a manifestação para um outro dia. As crianças não concordaram com as argumentações das professoras e saíram em passeata, gritando palavras de ordem, slogans do MST, o grito de guerra dos Sem Terrinha ${ }^{13}$ e dirigiram-se ao escritório da Cooperunião.

O episódio, para nós, pode ser hilário e para os dirigentes da Cooperunião pôde ser objeto de brincadeira, para as crianças, porém, tornouse objeto de conflito, pois na dimensão de sua vida de trabalho e estudo, o cuidado e a venda das mudas era um evento sério e importante. E, portanto, para os alunos o conflito foi real e grave.

Enquanto que a "educação bancária" (Freire, 1980) trata de manter o aluno apenas como objeto passivo do ato educativo, isto é, como receptáculo do conhecimento transmitido, a educação democrática busca fazer com que o educando seja um sujeito ativo, um construtor do conhecimento e que desenvolva as suas potencialidades "de forma omnilateral" (Manacorda, 1969).

Em suma, observamos que há uma grande autonomia na gestão da escola por parte da comunidade acadêmica, preservados os vínculos e as diretrizes gerais que emanam do MST. Em geral, embora exista uma hierarquia em relação à direção do Movimento, as escolas do MST apresentam um grau de radicalismo democrático que se encontra em divergência com a organização burocrática da escola oficial. 
Encerramos este item, afirmando, de modo semelhante a Makarenko, que as relações de produção pedagógicas, que têm seu núcleo na estrutura e dinâmica do poder, constituem-se em uma das mais importantes, ou até mesmo a mais importante, dimensões educativas da escola.

[...] considero que o decisivo na educação (na educação propriamente dita sem me referir às questões da instrução) não é o método de um determinado professor ou, inclusive, de uma escola, mas a organização da escola como coletividade e a organização do processo educativo (2002: 374).

Desta tese decorre a importância pedagógica da mudança de uma organização burocrática para uma democrática, lembrando que, em grande parte, essa mudança, no âmbito do MST, é propiciada pela luta de classes e pela alteração do modo de apropriação do excedente econômico em suas unidades econômicas, quando substitui o trabalho assalariado pelo trabalho associado.

\section{Conclusão}

Retomemos os propósitos deste artigo que foram primeiro o de mostrar que a posse da ECC pelas forças populares é um dos pré-requisitos para o exercício do controle na escola e, segundo, que a forma de controle encaminhada pela Cooperunião do MST é o autogoverno democrático. Estas características têm significativo impacto na prática pedagógica da escola, em particular na que diz respeito aos elementos escolares que mais imediatamente atuam sobre a formação das visões de mundo dos educandos. Além disso, mostramos que a organização da atividade educativa na ECC está baseada nas diretrizes pedagógicas do MST, cujos elementos básicos estão em correspondência com a práxis econômica e com a organização política de base do Movimento.

O trabalho associado de autogoverno democrático ${ }^{14}$ constitui uma espécie de infra-estrutura das ações e organizações educativas do MST, as organizações escolares engendradas são elas mesmas formas de trabalho associado informal ou potencial.

Para a pedagogia do MST, o ato pedagógico é em primeiro lugar uma questão política ou de poder. É preciso, antes de tudo, empregando a metáfora utilizada pelo Movimento, ocupar a escola. A ocupação da escola se 
encontra presidida e, ao mesmo tempo, fusionada com a luta social de professores, estudantes, funcionários, pais e comunidade para obterem o poder na escola capitalista pública e, simultaneamente, pela instauração de relações de produção pedagógicas mais democráticas, que é o método pelo qual a escola capitalista pode ser transfigurada.

Neste sentido, o exemplo da ECC acena com a possibilidade de se abrir um front verdadeiramente estratégico na sociedade atual, o da luta pela educação. Em termos concretos, isto significa, dentre outras coisas, tomar posse $^{15}$ das escolas do Estado de modo que estas de fato se tornem públicas, isto é, se tornem progressivamente as escolas controladas democraticamente pelas amplas massas que ganham a vida com o seu trabalho.

Com efeito, a escola examinada nos mostra arranjos organizacionais originais e peculiares. No âmago das relações pedagógicas, o que temos na escola considerada é uma associação não formal, mas, de fato, uma associação de gestão democrática conduzida por professores, alunos, pais de alunos e pela Cooperunião.

Encerramos este trabalho retomando numa frase a novidade presente no fio condutor desta história. As reformas capitalistas seculares, impulsionadas principalmente pelo Movimento Operário Popular, introduziram muitos melhoramentos na sociedade, porém, deixaram intacta a sua base, ou seja, as relações capitalistas de produção. Exatamente por isto, o capitalismo renega as reformas e trata de recuperar os seus privilégios originários. Neste contexto, o que o MST introduz na agenda política, ainda que de maneira parcial, é a tese de que os trabalhadores podem e devem dar início à reforma das relações capitalistas fundamentais: as relações de produção. Para tanto apresentam um modelo alternativo de apropriação do excedente econômico como método para encaminhar mudanças efetivamente transformadoras. Entretanto, tão pronto iniciaram esse processo se deram conta de que o mesmo não pode avançar se medidas concomitantes não forem tomadas no sentido de modificar também as relações de produção pedagógicas, uma vez que o novo modelo de apropriação demanda para seu funcionamento e possível progresso um novo tipo de inteligência social, um novo tipo de educação. 


\section{Notas}

1 Na elaboração e posterior aprovação da LDB/96, a ideologia neoliberal, por meio das diretrizes educacionais disseminadas principalmente pelo Banco Mundial, teve grande influência. No entanto, dado os limites deste texto não trataremos deste assunto aqui.

2 Os dados aqui trabalhados faziam parte de um projeto amplo que foi concluído em 2007.

3 Na visão do MST, pedagogia tende a ser identificada com educação. Entretanto, a educação, que envolve processos sociais, não se identifica necessariamente com pedagogia. Pedagogia é uma teoria sistematizada e que compreende princípios, teorias, didáticas, métodos etc. da educação e do ensino.

4 A sociedade capitalista criou a categoria social dos estudantes. O estudante não tem relação direta com o mundo do trabalho. Mesmo o estudante que é ao mesmo tempo um trabalhador, apresenta essa característica, pois o seu estatuto como aluno não mantém relação alguma com o de trabalhador.

5 As escolas do MST funcionam em forma de cooperativas. Essas cooperativas mantêm unidades de produção, ou seja, pequenas fábricas, campos de plantação, padarias, etc. e os produtos são colocados à venda.

6 Aluno A, nove anos de idade, coordenador da equipe pedagógica e comunicação da cooperativa ECC.

7 Aluna $B$, com dez anos de idade, secretária da equipe de serviços gerais da cooperativa ECC.

8 Aluna $\mathrm{C}$, onze anos de idade, coordenadora geral.

9 Aluno D, onze anos, coordenador da equipe de limpeza.

10 Uma outra forma fundamental de veiculação dos conhecimentos de história do Movimento e das classes trabalhadores encontra-se em atividade cotidiana realizada nas escolas e que se denomina mística (Dal Ri; Vieitez, 2004, 2008).

11 Entrevista coletiva realizada com os alunos da ECC.

12 O dirigente que nos narrou este fato disse que a negativa da compra foi uma brincadeira que a diretoria resolveu fazer com as crianças. Outra entrevistada, mãe de aluno, fez a seguinte observação quanto ao fato: "Eles [alunos] acabam se aperfeiçoando tanto que fazem as coisas às vezes melhor do que a gente grande. Uma época eles fizeram uma venda e veio a comissão negociar com a cooperativa. Só para judiar, o pessoal da cooperativa não quis negociar. Eles voltaram, fizeram uma reunião e vieram todos. Eles se reuniram todos na frente da cooperativa e gritavam. A criança só cresce. Acho muito bom. Uma coisa como essa eu vi aqui, nunca tinha visto em parte nenhuma".

13 Sem Terrinha é a denominação da organização política das crianças do MST.

14 Com respeito ao conceito de trabalho associado, ver Vieitez e Dal Ri (2001).

15 O controle da propriedade estatal não pode ser erigido sobre o princípio da propriedade privada. Entretanto, o controle de uma organização estatal por sua comunidade de trabalhadores, por exemplo, significa que esta detém em graus variáveis a sua posse. Usualmente, o tema autonomia escolar tangencia essa 
questão. Atualmente, as três universidades públicas paulistas, no Brasil, são exemplos bastante notáveis de autonomia no quadro da Ordem. A esse respeito ver Dal Ri (1997).

\section{Referências}

BAUDELOT, Christian \& ESTABLET, Roger (1976). La Escuela Capitalista en Francia. Madrid: Siglo Veintiuno.

BEZERRA NETO, Luiz (1999). Sem-Terra Aprende e Ensina. Estudo sobre as Práticas Educativas do Movimento dos Trabalhadores Rurais. São Paulo: Autores Associados.

BOWLES, Samuel \& GINTIS, Herbert (1976). Schooling in Capitalist America Educational Reform and the Contradictions of Economic Life. Massachusetts: Basic Books.

CALDART, Roseli S. (2000). Pedagogia do Movimento Sem Terra. Escola é mais do que escola. $2^{\mathrm{a}}$ ed. Rio de Janeiro: Vozes.

DAL RI, Neusa M. (1997). Sindicato, Autonomia e Gestão Democrática na Universidade. Tese de Doutorado em Educação. São Paulo: Faculdade de Educação da Universidade de São Paulo.

DAL RI, Neusa M. \& VIEITEZ, Candido G. ( 2004). A educação do movimento dos semterra. Revista Brasileira de Educação, ํㅡㄹ 26 . Rio de Janeiro: Anped: Autores Associados, pp. 44-57.

DAL RI, Neusa M. \& VIEITEZ, Candido G. (2008). Educação Democrática e Trabalho Associado no MST e nas Fábricas de Autogestão. São Paulo: Ícone/Fapesp.

FREIRE, Paulo (1971). Educação como Prática da Liberdade. $3^{\mathrm{a}}$ ed. Rio de Janeiro: Paz e Terra.

FREIRE, Paulo (1980). Pedagogia do Oprimido. 6 ${ }^{\mathrm{a}}$ ed. Rio de Janeiro: Paz e Terra.

LUEDEMANN, Cecília S. (2002). Anton Makarenko. Vida e Obra - A Pedagogia na Revolução. São Paulo: Expressão Popular.

MAKARENKO, Anton (2002a). Metodologia para a organização do processo educativo. In C. S. Luedemann, Anton Makarenko. Vida e Obra - A Pedagogia na Revolução. São Paulo: Expressão Popular.

MAKARENKO, Anton (2002b). De minha experiência de trabalho. In C. S. Luedemann, Anton Makarenko. Vida e Obra - A Pedagogia na Revolução. São Paulo: Expressão Popular.

MANACORDA, Mário A. (1969). Marx y la Pedagogía Moderna. Barcelona: Oikos-Tau.

MOVIMENTO DOS TRABALHADORES RURAIS SEM TERRA (1996). Princípios da Educação no MST. Porto Alegre: MST.

MOVIMENTO DOS TRABALHADORES RURAIS SEM TERRA (1999). Como fazemos a escola de educação fundamental. Caderno de Educação. MST, s.I., n. 9. 
MOVIMENTO DOS TRABALHADORES RURAIS SEM TERRA (2001a). Construindo o Caminho numa Escola de Assentamento do MST. Veranópolis: Iterra.

MOVIMENTO DOS TRABALHADORES RURAIS SEM TERRA (2001b). Pedagogia do Movimento Sem Terra - Acompanhamento às escolas. Boletim da Educação. Porto Alegre, ํo 8 .

PISTRAK, Moisei M. (2002) Fundamentos da Escola do Trabalho. São Paulo: Expressão Popular.

PRAIS, Maria de Lurdes M. (1990). Administração Colegiada na Escola Pública. Campinas: Papirus.

VIEITEZ, Candido G. \& DAL RI, Neusa M. (2001). Trabalho Associado. Cooperativas e Empresas de Autogestão. Rio de Janeiro: DP\&A.

\section{DEMOCRATIC MANAGEMENT IN PUBLIC SCHOOLS: AN EDUCATIONAL EXPERIENCE OF THE MST}

\section{Abstract}

The purpose of this work is to discuss the pedagogy of Movimento dos Trabalhadores Sem Terra through the analysis of the main pedagogical elements present in the Escola Municipal de Ensino Fundamental Construindo o Caminho. The school which is ruled by the Movimento has different functioning and organization of those usually found in official schools, highlighting educational categories as: union between teaching and work, and democratic administration shared by students, teachers, other workers and community.

Keywords

Democratic education; Self-administration; MST; Work 


\section{LA GESTIÓN DEMOCRÁTICA EN LAS ESCUELAS PÚBLICAS: UNA EXPERIENCIA} EDUCATIVA DEL MST

Resumen

En este trabajo tenemos por objetivo discutir la pedagogía del Movimento dos Trabalhadores Rurais Sem Terra, de Brasil. Esto es hecho a través del análisis de los elementos pedagógicos fundamentales que se encuentran en un objeto que tomamos como mediador, la Escola Municipal de Ensino Fundamental Construindo o Caminho. La investigación nos ha enseñado que esa escuela pública, sobre la cual el Movimento detiene una suerte de posesión, se encuentra organizada y funciona según un parangón muy distinto al que se suele encontrar en las escuelas oficiales. Entre otras categorías educacionales que repuntan en ese modo de organización y actuación subrayamos la unión de trabajo y enseñanza, la autogestión compartida por profesores, empleados, alumnos y la comunidad.

Palabras clave

Educación democrática; Autogestión; MST; Trabajo

Recebido em Novembro/2008 Aceite para publicação em Novembro/2009

Toda a correspondência relativa a este artigo deve ser enviada para: Neusa Maria Dal Ri, Avenida Rio Branco, 339, Apartamento 11, Marília, São Paulo, Brasil, CEP-17500-090. E-mail: neusamdr@terra.com.br 